(2) Open Access Full Text Article

\title{
Intraocular pressure reduction using a fixed combination of timolol maleate $0.5 \%$ and brimonidine tartrate $0.2 \%$ administered three times daily
}

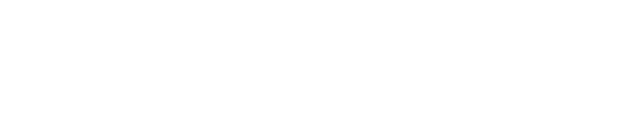

\section{Elad Moisseiev \\ Shimon Kurtz \\ Moshe Lazar \\ Gabi Shemesh}

Department of Ophthalmology, Tel Aviv Sourasky Medical Center, Tel Aviv, Israel
Correspondence: Elad Moisseiev Department of Ophthalmology, Tel Aviv Sourasky Medical Center, Weitzman 6 Street, Tel Aviv, 64239, Israel

$\mathrm{Tel}+97236973408$

Fax +97236973870

Email elad_moi@netvision.net.il
Background: The purpose of this study was to evaluate the safety and efficacy of a fixed combination of timolol maleate $0.5 \%+$ brimonidine tartrate $0.2 \%\left(\right.$ Combigan $\left.^{\circledR}\right)$ for reduction for intraocular pressure (IOP) in patients with glaucoma when the dose frequency is increased from twice to three times daily.

Methods: The patients included had either primary open angle glaucoma or ocular hypertension. Those who were previously on treatment completed a drug washout period prior to inclusion. IOP was measured at baseline, after 4 weeks of treatment with Combigan twice daily, and again after a further 4 weeks of Combigan three times daily. Blood pressure, heart rate, and oxygen saturation were also recorded at each assessment.

Results: Thirty-one eyes from 31 patients were included. Increasing the Combigan dose frequency resulted in a statistically significant $(P<0.001)$ additional reduction in IOP of $2.25 \pm 1.18 \mathrm{mmHg}$, corresponding to a further $10.3 \%$ reduction in IOP from baseline. No local or systemic adverse effects were documented.

Conclusion: Treatment with Combigan three times daily was more effective in reducing IOP than the twice-daily regimen, with no increase in adverse effects.

Keywords: Combigan ${ }^{\circledR}$, timolol, brimonidine, glaucoma, dose frequency

\section{Introduction}

Glaucoma is one of the most common causes of chronic visual impairment ${ }^{1}$ and the second leading cause of blindness worldwide. ${ }^{2}$ Elevated intraocular pressure (IOP) is the most important prognostic risk factor for vision loss in glaucoma. ${ }^{3,4}$ Large-scale clinical studies have demonstrated the importance of early IOP reduction in order to prevent optic nerve damage and visual loss. ${ }^{5-8}$ Specifically, the Early Manifest Glaucoma Trial showed that every $1 \mathrm{mmHg}$ reduction in IOP is important and associated with an approximately $10 \%$ reduction in the risk of disease progression. ${ }^{8}$

First-line treatment typically consists of monotherapy with a single agent, and if the IOP reduction is inadequate, treatment is switched to an alternative monotherapy or is combined with a second agent. ${ }^{9}$ In patients requiring treatment with more than one agent, a fixed combination therapy is usually preferred because it is associated with increased compliance. ${ }^{10-12}$ However, it has been shown that, in reality, combination therapy is often administered as first-line therapy for patients diagnosed with primary open angle glaucoma or ocular hypertension. ${ }^{11,13}$ 
Combigan $^{\circledR}$ (Allergan Inc, Irvine, CA, USA) is a combination treatment for glaucoma, and consists of a fixeddose combination of timolol maleate $0.5 \%$ (a nonselective beta-blocker) and brimonidine tartrate $0.2 \%$ (a selective alpha-2 agonist). Combigan has been demonstrated to be superior to monotherapy using either timolol or brimonidine in IOP reduction, ${ }^{14,15}$ as well as in reducing fluctuations in IOP. ${ }^{16}$ This combination therapy had no additive or interactive effects with regard to adverse events, ${ }^{14-16}$ and was even shown to have a lower incidence of ocular allergy compared with brimonidine monotherapy. ${ }^{17}$ Several studies have demonstrated Combigan to be more effective than other combinations for IOP reduction ${ }^{18,19}$ and to have a better tolerability profile. ${ }^{19,20}$

All studies of Combigan have used a twice-daily dosing regimen. The recommended frequency of administration for its components is twice daily for timolol and three times daily for brimonidine. ${ }^{14-16,21,22} \mathrm{~A}$ literature search did not identify any studies in which Combigan was administered three times daily. The purpose of this study was to assess the safety and efficacy of increasing the Combigan dosage from twice to three times daily for IOP reduction.

\section{Materials and methods}

Thirty-one eyes from 31 patients were included. All patients were 18 years or older, and were diagnosed with primary open angle glaucoma or ocular hypertension by a glaucoma specialist (GS or SK) after undergoing a detailed ophthalmologic examination, including evaluation of glaucomatous optic disc damage by gonioscopy, and IOP measurements by applanation tonometry and automated perimetry.

Exclusion criteria included closed angle, neovascular, or uveitic glaucoma. Patients with advanced glaucoma, defined as a mean deviation less than $12 \mathrm{~dB}$ or presence of central scotoma, were also ineligible. Patients receiving systemic treatment with beta-blockers were also excluded, as were patients with systemic conditions that may be adversely affected by timolol or brimonidine, including asthma, hypotension, bradycardia, cardiac arrhythmia, and impaired renal or hepatic function. Patients who had previously undergone surgery or laser treatment for their glaucoma were also ineligible.

All patients had visual acuity of 20/80 or better. Only one eye of each patient was included in the study. In patients with both eyes meeting the inclusion criteria, the right eye was routinely chosen as the study eye. The patients included in this study were either newly diagnosed and previously untreated or had been previously treated by only one IOPlowering agent. Treatment-naive patients were treated with
Combigan twice daily for 4 weeks, after which the dosage was increased to three times a day for another 4 weeks. Previously treated patients underwent a washout period (1 week for alpha agonists, carbonic anhydrase inhibitors, and prostaglandin analogs, and 2 weeks for beta-blockers) after which they were treated with Combigan twice daily for 4 weeks and then three times daily for a further 4 weeks. Patients were instructed to instill 1 drop of Combigan in their study eye every 12 hours during the first 4 weeks, and every 8 hours during the following 4 weeks. The patients were instructed to instill the drops between 10 am and noon and between $10 \mathrm{pm}$ and midnight during the first 4 weeks, and then between 6 am and $8 \mathrm{am}, 2 \mathrm{pm}$ and $4 \mathrm{pm}$, and $10 \mathrm{pm}$ and midnight during the next 4 weeks.

Intraocular pressure was measured in all patients at baseline, after 4 weeks of treatment with Combigan twice daily, and after a further 4 weeks of treatment with Combigan three times daily. Baseline measurements were taken after the washout period in patients who had received prior therapy in order to eliminate the effect of pretreatment. All measurements were done using Goldmann applanation tonometry, and were performed by a single ophthalmologist (GS). All measurements were taken between 8 am and $10 \mathrm{am}$, prior to instillation of the morning dose of Combigan.

Heart rate, blood pressure, and blood oxygen saturation were also measured at each assessment point. Heart rate and blood pressure were measured using an automatic device and oxygen saturation by pulse oximeter. All measurements were done by the same physician (GS) at the time of IOP measurement.

The study protocol followed the tenets of the Declaration of Helsinki, was reviewed and approved by the institutional review board, and written informed consent was obtained from all participants.

\section{Statistical analysis}

Descriptive statistics, including the mean and standard deviation, were generated for all continuous study variables. The statistical significance of changes in IOP, systolic and diastolic blood pressure, heart rate, and oxygen saturation at the different assessment points was assessed using the Student's $t$-test. The statistical significance level was set at 0.05 . The data were analyzed using the Statistical Package for the Social Sciences version 17.0 software (SPSS Inc, Chicago, IL, USA).

\section{Results}

Thirty-one eyes from 31 patients were included in the study. The patients comprised 21 men (67.7\%) and 10 women 
$(32.3 \%)$ of mean age $74.6 \pm 7.6(55-88)$ years. At baseline, mean IOP was $21.7 \pm 2.87$ (16-29) $\mathrm{mmHg}$. Mean systolic and diastolic blood pressure values were $152.16 \pm 15.43 \mathrm{mmHg}$ and $76.8 \pm 9.85 \mathrm{mmHg}$, respectively. Mean heart rate was $76.03 \pm 11.27$ beats per minute and mean oxygen saturation was $98.25 \pm 1.23 \%$.

After 4 weeks of treatment with Combigan twice daily, mean IOP was 16.03 $\pm 2.25(10-20) \mathrm{mmHg}$. Mean systolic and diastolic blood pressure values were $146.87 \pm 13.21 \mathrm{mmHg}$ and $73.25 \pm 10.17 \mathrm{mmHg}$, respectively. Mean heart rate was $72.96 \pm 10.64$ beats per minute and mean oxygen saturation was $98.13 \pm 1.89 \%$.

After a further 4 weeks of treatment with Combigan three times daily, mean IOP was $13.77 \pm 2.14$ (8-18) $\mathrm{mmHg}$. Mean systolic and diastolic blood pressure values were $145.58 \pm 15.75 \mathrm{mmHg}$ and $74.38 \pm 10.63 \mathrm{mmHg}$, respectively. Mean heart rate was $71.61 \pm 10.73$ beats per minute and mean oxygen saturation was $98.22 \pm 0.92 \%$. The data are presented in Table 1.

After treatment with Combigan twice daily for 4 weeks, IOP was reduced by a mean of $5.67 \pm 1.86 \mathrm{mmHg}$, corresponding to a mean reduction of $26.12 \%$ compared with baseline IOP, which was statistically significant $(P<0.001)$.

Comparing IOP measurements after 4 weeks of treatment with Combigan twice daily and after a further 4 weeks of Combigan three times daily showed an additional reduction in IOP, which varied between $0 \mathrm{mmHg}$ and $4 \mathrm{mmHg}$. The increased dosage resulted in a mean additional IOP reduction of $2.25 \pm 1.18 \mathrm{mmHg}$, corresponding to a mean reduction of a further $10.3 \%$ of the baseline IOP. This reduction was statistically significant $(P<0.001)$. The data are presented in Figure 1.

Changes in systolic and diastolic blood pressure, heart rate, and oxygen saturation between the three assessment points were not statistically significant. There were no complaints of ocular surface irritation, and no patient suffered any systemic or local adverse effect that required cessation of Combigan therapy.

\section{Discussion}

In this study, treatment with Combigan twice daily resulted in a mean IOP reduction of $26.12 \%$, comparable with the results of previous efficacy studies. ${ }^{14,16,18-20,23,24}$ This effect on IOP was expected, given that patients included in this study were previously untreated or had undergone a drug washout period. After a further 4 weeks of treatment at the increased Combigan dosage of three times daily, IOP decreased by a further $2.25 \pm 1.18 \mathrm{mmHg}$, corresponding to a further mean reduction of $10.3 \%$ of the baseline IOP value. The increased dosage was not associated with any significant systemic adverse effects or any change in blood pressure, heart rate, or oxygen saturation, nor with any local adverse effects or intolerability.

These results are similar to those of a previous study by our group which compared twice daily and three times daily treatment with Cosopt ${ }^{\circledR}$ (Merck and Co, Inc, Whitehouse Station, NJ, USA), a fixed-dose combination of maleate timolol $0.5 \%$ and dorzolamide $2.0 \%{ }^{25}$ It was shown that increasing the Cosopt dosage caused an additional reduction of $2.2 \pm 1.58 \mathrm{mmHg}$ in IOP, corresponding to a decrease of $10.69 \%$ of the baseline value. Both Combigan and Cosopt are combined formulations that include one agent which is usually administered twice daily as monotherapy (timolol) and a second agent which requires administration three times daily (brimonidine and dorzolamide, respectively). The results of this study and our previous research show that using the combination treatments three times daily results in increased IOP reduction with no increase in systemic or local side effects. The usual twice-daily regimen

Table I Mean and standard deviation of IOP, systolic and diastolic blood pressure, heart rate and oxygen saturation levels at baseline, after 4 weeks of treatment with Combigan twice a day, and after 4 weeks of treatment with Combigan three times a day

\begin{tabular}{|c|c|c|c|c|c|c|c|c|c|c|}
\hline \multirow[t]{2}{*}{ Timepoint } & \multicolumn{2}{|c|}{ IOP (mmHg) } & \multicolumn{2}{|c|}{$\begin{array}{l}\text { Systolic blood } \\
\text { pressure }(\mathrm{mmHg})\end{array}$} & \multicolumn{2}{|c|}{$\begin{array}{l}\text { Diastolic blood } \\
\text { pressure }(\mathrm{mmHg})\end{array}$} & \multicolumn{2}{|c|}{ Heart rate (bpm) } & \multicolumn{2}{|c|}{$\begin{array}{l}\text { Oxygen } \\
\text { saturation } \\
\text { levels (\%) }\end{array}$} \\
\hline & Mean & SD & Mean & SD & Mean & SD & Mean & SD & Mean & SD \\
\hline Baseline & 21.7 & 2.87 & 152.16 & 15.43 & 76.8 & 9.85 & 76.03 & 11.27 & 98.25 & 1.23 \\
\hline $\begin{array}{l}\text { After } 4 \text { weeks of } \\
\text { Combigan } X 2 / d\end{array}$ & 16.03 & 2.25 & 146.87 & 13.21 & 73.25 & 10.17 & 72.96 & 10.64 & 98.13 & 1.89 \\
\hline $\begin{array}{l}\text { After } 4 \text { weeks of } \\
\text { Combigan } \times 3 / d\end{array}$ & 13.77 & 2.14 & 145.58 & 15.75 & 74.38 & 10.63 & 70.61 & 10.73 & 98.22 & 0.92 \\
\hline
\end{tabular}

Note: Only the differences in IOP were of statistical significance (highlighted).

Abbreviations: IOP, intraocular pressure; SD, standard deviation; bpm, beats per minute. 


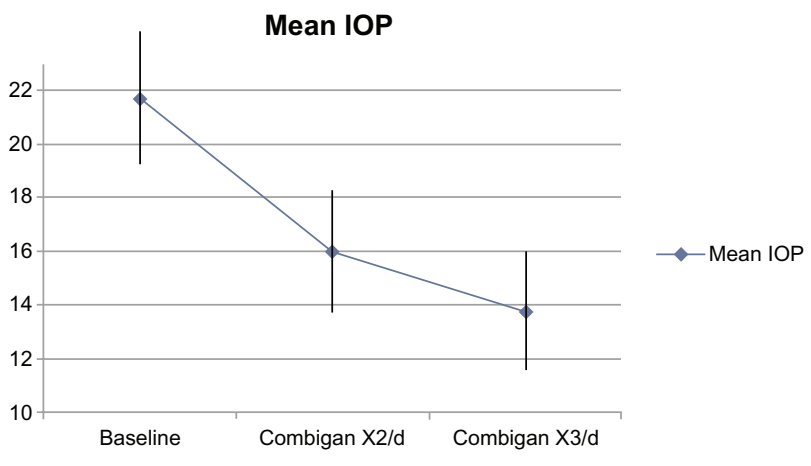

Figure I Mean intraocular pressure values at baseline, after 4 weeks of Combigan ${ }^{\circledR}$ twice daily, and after another 4 weeks of Combigan three times daily. Differences in intraocular pressure between the three assessment times are statistically significant.

Abbreviation: IOP, intraocular pressure.

may limit the efficacy of these combinations because one of their components is underdosed. In the present study, we believe that increasing the brimonidine component to its recommended dosing for full effect was responsible for the increased efficacy in lowering IOP.

The strengths of this study include its prospective nature, exclusion of patients with glaucoma other than primary open angle glaucoma or ocular hypertension, and its open-label design, emulating the real-life clinical setting. Potential limitations include its relatively small cohort size and short treatment duration. However, the purpose of the study was to assess the effect of increasing Combigan dosage from twice to three times daily on IOP; the study was designed for this comparison and revealed statistically significant results. The timing of IOP measurement is another potential limitation, in that the morning measurements could have reflected trough IOP values and may not be representative of daily fluctuations.

The findings of this study are clinically important, because increasing the Combigan dosage achieved a statistically significant additional reduction in IOP, with no change in the safety profile. It has been demonstrated that every $1 \mathrm{mmHg}$ reduction in IOP is associated with an approximately $10 \%$ reduction in the risk of progression of glaucoma, ${ }^{8}$ and this strategy may be a safe and effective means for achieving a further clinically significant IOP reduction.

In conclusion, we found that Combigan administered three times daily is more effective than and as safe as twicedaily administration. Based on our results, we suggest that the Combigan dosage should be increased to three times daily in patients with primary open angle glaucoma or ocular hypertension, in whom a small but significant additional reduction in IOP is beneficial. We conclude that in patients who are not prone to the adverse effects of beta-blocker therapy, overdosing timolol by one drop a day is more effective than and as safe as underdosing brimonidine by one drop a day. Therefore, we recommend that for patients with primary open angle glaucoma or ocular hypertension who are already using Combigan and for whom further IOP reduction is needed, increasing the dose frequency to three times daily should be tried before changing or adding other medications, or considering surgery. Further large-scale studies are required to corroborate our findings and establish their value in clinical practice.

\section{Disclosure}

The authors report no conflict of interest in this work.

\section{References}

1. Lee AG, Beaver HA. Visual loss in the elderly - Part I. Chronic visual loss: what to recognize and when to refer. Clin Geriatr. 2003;11: 46-53.

2. Resnikoff S, Pascolini D, Etya'ale D, Kocur I, Pararajasegaram R, Pokharel GP, et al. Global data on visual impairment in the year 2002. Bull World Health Organ. 2004;82:844-851.

3. Nouri-Mahdavi K, Hoffman D, Coleman AL, et al. Advanced Glaucoma Intervention Study. Predictive factors for glaucomatous visual field progression in the Advanced Glaucoma Intervention Study. Ophthalmology. 2004;111:1627-1635.

4. Bengtsson B, Leske MC, Hyman L, Heijl A. Early Manifest Glaucoma Trial Group. Fluctuation of intraocular pressure and glaucoma progression in the Early Manifest Glaucoma Trial. Ophthalmology. 2007;114:205-209.

5. Leske MC, Heijl DK, Hussein M, Bengtsson B, Hyman L, Komaroff E. Early Manifest Glaucoma Trial Group. Factors for glaucoma progression and the effect of treatment: the Early Manifest Glaucoma Trial. Arch Ophthalmol. 2003;121:48-56.

6. Kass MA, Heuer DK, Higginbotham EJ, et al. The Ocular Hypertension Treatment Study: a randomized trial determines that topical ocular hypotensive medication delays or prevents the onset of primary openangle glaucoma. Arch Ophthalmol. 2002;120:701-713.

7. Heijl A, Leske MC, Bengtsson B, Hyman L, Bengtsson B, Hussein M. Early Manifest Glaucoma Trial Group. Reduction of intraocular pressure and glaucoma progression: results from the Early Manifest Glaucoma Trial. Arch Ophthalmol. 2002;120:1268-1279.

8. Leske MC, Heijl A, Hyman L, Bengtsson B, Komaroff E. Factors for progression and glaucoma treatment: the Early Manifest Glaucoma Trial. Curr Opin Ophthalmol. 2004;15:102-106.

9. European Glaucoma Society. Terminology and Guidelines for Glaucoma, 3rd ed. Savona, Italy: Editrice Dogma Srl; 2008.

10. Remo SJ, Wang-Pui S. Comparison of latanoprost with fixed combination dorzolamide and timolol in adult patients with elevated intraocular pressure: an eight week, randomized, open-label, parallel-group, multicenter study in Latin America. Clin Ther. 2004;26: 755-756.

11. Gugleta K, Orgul S, Flammer J. Experience with Cosopt, the fixed combination of timolol and dorzolamide, after switch from free combination of timolol and dorzolamide, in Swiss ophthalmologists' offices. Curr Med Res Opin. 2003;19:330-335.

12. Choudhri S, Wand M, Shields MB. A comparison of dorzolamidetimolol combination versus the concomitant drugs. Am J Ophthalmol. 2000;130:832-833.

13. Crichton AC, Harasymowycz P, Hutnik CM, et al. Effectiveness of dorzolamide-timolol (COSOPT) in patients who were treatment naive for open-angle glaucoma or ocular hypertension: the COSOPT first-line study. J Ocul Pharmacol Ther. 2010;26:503-511. 
14. Craven ER, Walters TR, Williams R, Chou C, Cheetham JK, Schiffman R. Combigan Study Group. Brimonidine and timolol fixedcombination therapy versus monotherapy: a 3-months randomised trial in patients with glaucoma or ocular hypertension. J Ocul Pharm Ther. 2005;21:337-348.

15. Larsson LI. Aqueous humor flow in normal human eyes and treated with brimonidine and timolol, alone and in combination. Arch Ophthalmol. 2001;119:492-495.

16. Spaeth GL, Bernstein P, Caprioli J, Schiffman RM. Control of intraocular pressure and fluctuation with fixed-combination brimonidine-timolol versus brimonidine or timolol monotherapy. Am J Ophthalmol. 2011;151:93-99.

17. Motolko M. Comparison of allergy rates in glaucoma patients receiving brimonidine $0.2 \%$ monotherapy versus fixed-combination brimonidine $0.2 \%$ - timolol 0.5\% therapy. Curr Med Res Opin. 2008;24: 2663-2667.

18. García-Feijoó J, Sáenz-Francés F, Martínez-de-la-Casa JM, et al. Comparison of ocular hypotensive actions of fixed combinations of brimonidine/timolol and dorzolamide/timolol. Curr Med Res Opin. 2010;26:1599-1606.

19. Lanzl I, Raber T. Efficacy and tolerability of the fixed combination of brinzolamide $1 \%$ and timolol $0.5 \%$ in daily practice. Clin Ophthalmol. 2011;5:291-298.
20. Gulkilik G, Oba E, Odabast M. Comparison of fixed combinations of dorzolamide/timolol and brimonidine/timolol in patients with primary open-angle glaucoma. Int Ophthalmol. 2011;31:477-451.

21. Rahman MQ, Ramaesh K, Montgomery DM. Brimonidine for glaucoma. Expert Opin Drug Saf. 2010;9:483-491.

22. Fudemberg SJ, Batiste C, Katz LJ. Efficacy, safety, and current applications of brimonidine. Expert Opin Drug Saf. 2008;7:795-799.

23. Papaconstantinou D, Georgalas I, Kourtis N, et al. Preliminary results following the use of fixed combination of timolol-brimonidine in patients with ocular hypertension and primary open-angle glaucoma. Clin Ophthalmol. 2009;3:227-230.

24. Katz LJ, Rauchman SH, Cottingham AJ, et al. Fixed-combination brimonidine-timolol versus latanoprost in glaucoma and ocular hypertension: a 12-week, randomized, comparison study. Curr Med Res Opin. 2012;28:781-788.

25. Shemesh G, Moisseiev E, Lazar M, Kurtz S. Intraocular pressure reduction of fixed combination timolol maleate $0.5 \%$ and dorzolamide 2\% (Cosopt) administered three times a day. Clin Ophthalmol. 2012;6: $283-287$.
Clinical Ophthalmology

\section{Publish your work in this journal}

Clinical Ophthalmology is an international, peer-reviewed journal covering all subspecialties within ophthalmology. Key topics include: Optometry; Visual science; Pharmacology and drug therapy in eye diseases; Basic Sciences; Primary and Secondary eye care; Patien Safety and Quality of Care Improvements. This journal is indexed on

Submit your manuscript here: http://www.dovepress.com/clinical-ophthalmology-journal

\section{Dovepress}

PubMed Central and CAS, and is the official journal of The Society of Clinical Ophthalmology (SCO). The manuscript management system is completely online and includes a very quick and fair peer-review system, which is all easy to use. Visit http://www.dovepress.com/ testimonials.php to read real quotes from published authors. 